\title{
Sweeteners in Diet Chocolate Ice Cream: Penalty Analysis and Acceptance Evaluation
}

\author{
Palazzo A. B. \\ Department of Food and Nutrition \\ School of Food Engineering / University of Campinas - UNICAMP - Campinas / Brazil
}

Bolini H. M. A.

Department of Food and Nutrition

School of Food Engineering / University of Campinas - UNICAMP - Campinas / Brazil

Received: January 31, 2017 Accepted: February 21, 2017 Published: February 23, 2017

doi:10.5296/jfs.v6i1.10655

URL: https://doi.org/10.5296/jfs.v6i1.10655

\begin{abstract}
According to the consumers' demand for healthy and nutritional food without loss of sensory perception, a study based on sucrose substitution appears to be interesting for the food industries. Thus, this study associated the most significant attributes of diet chocolate ice cream aimed to obtain a high acceptance. The difference between the ice cream samples was related to sucrose concentration $(12,14,16,18$ and 20\%). Groups of 122 potential consumers of chocolate ice creams took part in an affective test using a nine-centimeter unstructured scale. The same group analyzed the samples using a 7-point Just About Right scale (JAR) regarding sweetness, chocolate flavor and smoothness. A Penalty analysis was used to identify potential directions for the ice cream's improvement, based on consumer tests. After choosing the best formulation of the sucrose sample, a magnitude estimation procedure was performed. The sweeteners used to replace the sucrose were: sucralose, stevioside, neotame, neosucralose and an aroma blend (aroma/sucrose). Penalty analysis based on JAR scales showed that smoothness and chocolate flavor were the most penalizing sensory characteristics causing significant drop in chocolate ice cream acceptability. Thus, the aroma
\end{abstract}


compound and neosucralose blend showed the best sucrose replacements.

Keywords: Penalty analysis, Diet, Ice cream, Sweeteners, Sensory analysis

\section{Introduction}

Ice cream is a dairy product consumed worldwide, well accepted among all age consumers (Cadena et al., 2012; Sun-Waterhouse et al., 2013). Nowadays, different efforts between the food industry and the academic field have improved studies using ice cream replacements (Aykan et al., 2008) or sucrose substitution (Cadena \& Bolini, 2011; Ozdemir et al., 2015).

A study used grape juice concentrate and sugarcane molasses as partial sucrose replacements in chocolate ice cream (Soukoulis \& Tzia, 2010), showed that both ingredients improved creamy texture, however, they must be used as partial sucrose replacement.

According to Fonseca et al. (2016), a sensory profile of six commercial chocolate ice creams was evaluated, using the "comment analysis" and "pivot profile" methods. The attributes more appreciated were creaminess, brown color, and chocolate aroma, followed by sweet taste, chocolate flavor, dark chocolate flavor, and melting point.

Sucrose replacement using sweeteners in foods needs complex sensory studies to evaluate the correctly amount of each ingredient to be used. This occurs because sweeteners have particular characteristics in different kinds of foods and beverages and may promote undesirable effects, like taste changes, as residual taste (Cadena \& Bolini 2012; Paixão et al., 2014).

To decrease this effect, Just-About-Right (JAR) can be used (Morais et al., 2014). Besides, JAR scales and attribute liking questions are usually used to study consumer perception of the sensory characteristics of food products (Ares et al., 2008).

A Penalty analysis is used to relate JAR scales to liking data, mainly in order to know which side of the JAR scale was linked to lower hedonic ratings (Laguna et al., 2013). Furthermore, this analysis could be a useful tool to identify directions for the product improvement, as reported by Cervantes et al. (2010) and was used in order to help the understanding of most accepted attributes (Plaehn \& Horne, 2008).

Usually, the high intensity sweeteners are being used such as neotame, sucralose, thaumatin, and stevioside (Cardoso \& Bolini, 2008; Palazzo \& Bolini, 2014) and blend neosucralose ((acesulfame-K/sucralose/neotame (100:50:1)) (Cadena et al., 2013). Neotame is an artificial sweetener, which was developed recently, while stevioside is natural, better known and used with high expression.

Ozdemir et al. (2015) studied four different ice cream samples, produced using sucrose and stevia as sweetener. As result, they concluded that stevia could be used for the production of ice cream for diabetic patients and that samples increased the quality of the product.

Some studies with sucrose replacement in ice cream were conduced, but with different high sweeteners and bulking agents. Maia et al. (2008) reported a study about consumer preference for ice cream formulations (vanilla, strawberry and chocolate) sweetened with sucrose and xylitol. The ice creams sweetened with sucrose were preferred when compared to those sweetened with xylitol. Furthermore, the chocolate sample showed the lowest sensory difference, followed by strawberry and vanilla ice creams. 


\section{Macrothink}

The studied chemical aromatic compound used maltodextrin as vehicle, and all the substances were rightly approved by the FDA (Food and Drug Administration, USA) and registered at the FEMA (Flavor and Extract Manufacturers Association of the United States, Washington, DC, USA).

\section{Material and Methods}

All dry materials were dispersed under agitation into the liquid ingredients using a mechanical mixer (Siemsen Ltda, Brazil). After the addition of the emulsifier/stabilizer, the liquid was mixed in a Cuisinart Frozen Yogurt-Ice Cream mixer during 15 minutes. Then, the ice cream samples were frozen at $-10 \mathrm{C}$ and remained at constant temperature using a batch freezer (Consul Freezer 530, Brazil). All samples were packaged into $1000 \mathrm{~mL}$ high-density polyethylene containers (Kopus, Brazil).

\subsection{Diet Chocolate Ice Cream for JAR Test}

The ice cream formulations had the following composition: $10 \%$ fat powdered milk (Consulat, Brazil); sucrose (concentration varying on 12, 14, 16, 18 and 20\%); cocoa powder (Cargill Foods, Brazil); 0.7\% emulsifier/stabilizer (mono and diglycerides of fatty acids, Emustab, Duas Rodas, Brazil), vegetable fat (Mesa, Brazil).

\subsection{Sensory Analysis}

The chocolate ice cream samples were presented in white disposable plastic cups containing one scoop (each scoop was about $15 \mathrm{~g}$ ) adequate to evaluate the affective test. Each sample was coded with a three-digit random number and panelists were also provided with bottled mineral water for palate rinse.

Tests were carried out in individual air-conditioned booths $\left(22{ }^{\circ} \mathrm{C}\right)$ in the Sensory Analysis Laboratory/School of Food Engineering (FEA/Unicamp) and evaluated under white light, thus ensuring comfort and privacy for the panelists. A complete balanced block was used (MACFIE et al., 1989) and the samples were presented sequentially in a monadic way.

The consumer group, $(\mathrm{n}=122)$, was composed by students and laboratory staff. The selection criterion was that subjects had to be regular consumers of dairy ice cream. Those consumers examined the samples using a Just-About-Right scale within seven points $(1=$ much too weak, $4=$ JAR, 7 = much too strong).

The attributes evaluated by the consumers were: sweetness, chocolate flavor and smoothness. The smoothness attribute was defined as the one orally perceived through a smooth texture, without any defects and melting uniformly to thick and homogeneous fluid (Soukoulis \& Tzia, 2010).

Also, the consumers were asked to evaluate the overall liking of the samples using a 9-point hedonic scale.

\subsection{Diet Chocolate Ice cream for Magnitude Estimation}

A traditional sample (sweetened only with sucrose) and three other samples were developed, differing in their sweetener: 0.0169\% sucralose (Suc) (Tovani Benzaquen, Brazil); 0.087\% stevioside (Ste) (Funcional Mikron, Brasil); 0.0017\% neotame (Neo) (SweetMix, Brazil); $0.033 \%$ of the neosucralose blend (BL1) ((acesulfame-K/sucralose/neotame (100:50:1)) (SweetMix, Brazil) and $0.24 \%$ of the aroma blend (BL2) (Chemical aromatic compound 


\section{Ml Macrothink}

SXT2852, Sensient Technologies Brazil, Jundiaí, SP, Brazil). The chocolate ice cream samples were prepared using $16.5 \%$ fat powered milk (Consulat), $61.5 \%$ water, $2.8 \%$ cocoa power, $4.5 \%$ vegetal fat, $0.7 \%$ stabilizer/emulsifier and Polydextrose and Maltitol (Tovani Benzaquen, Brazil) were used as bulking agents. A control (traditional) sample was also formulated with $14 \%$ sucrose (Tra).

\subsection{Equi-sweetness Determination}

The equi-sweetness determination was performed according to the magnitude estimation test (Stone \& Oliver, 1969). Twenty-five panelists were selected according to their discriminating power assessed by Wald's sequential analysis (Amerine et al., 1965). The training panel consisted of a methodology explanation, including the correct use of the scale and the evaluating of samples with different sweetness levels, with higher and lower concentrations than the reference sample.

Five samples with different sucrose concentrations $(12,14,16,18$ and 20\%) and a reference sample (sweetened with $14 \%$ sucrose, coded as R) were presented to the panelists.

The equi-sweetness concentrations used were based on data from available literature (Marcellini et al., 2005; Cardoso \& Bolini 2007; Palazzo et al., 2011). The multiplication factor of 1.6 was adopted (Marcellini et al., 2005; Cardoso \& Bolini, 2007).

The assessors received a reference sample (R) with sweetness intensity designated by the arbitrary value 100, followed by several samples with higher or lower sweetness intensity. They were asked to estimate the sweetness intensity comparing them to the reference sample. For data analysis, the estimated sweetness magnitude values were converted to logarithmic values and expressed using the geometric mean. The data were collected using the FIZZ Sensory Network program (Biosystemes, Couternon, France).

\subsection{Consumer Panel}

The diet chocolate ice cream samples were prepared according to the equi-sweetness results and were presented in white disposable plastic cups $(15 \mathrm{~g})$ to evaluate the affective test. Each sample was coded with a three-digit random number and tests were carried out in individual air-conditioned booths $\left(22{ }^{\circ} \mathrm{C}\right)$ in the Sensory Analysis Laboratory/School of Food Engineering (FEA/Unicamp).

The consumer group, $(\mathrm{n}=116)$, composed by students and laboratory staff, was asked to evaluate the appearance, aroma, flavor, texture and overall liking of the samples using a 9-point hedonic scale.

\subsection{Statistical Analysis}

\subsubsection{Penalty Analysis}

Data from JAR scales were analyzed by dividing the scale into three parts: below 7 (too little), 7 (JAR) and above 7 (too much). The percentage of respondents scoring in each category was calculated for each sample.

The respondent percentages (x-axis) were plotted against the penalties (y-axis), and an attribute was considered significant when the respondent percentage was higher than $20 \%$ (Xiong \& Meullenet, 2006; Laguna et al., 2013) and the penalty score (drop in overall liking) was higher than 1. 


\section{Macrothink}

This statistical analysis was carried out using Xlstat-Mx (Xlstat, New York, NY, USA).

\subsubsection{Acceptance Analysis}

An analysis of variance (ANOVA) was performed on the consumers' overall liking scores, and mean ratings were calculated using Tukey's test $(\mathrm{p}=5 \%)$. Statistical calculations were generated by the Statistical Analysis System - SAS (2003) program.

\section{Results and Discussion}

The consumers' opinion was observed using the JAR scale in relation to sweetness, chocolate flavor and smoothness. Just About Right scales measure the attribute's adequate level and they are used to determine the best sensory parameters levels in a product.

\subsection{The Ideal Sucrose Concentration}

The affective means of overall liking were described in Table 1 and the results showed no significant difference among samples using 12,14 and $18 \%$ sucrose $(p \leq 0.05)$. Regarding the JAR scale results, the ice cream with $14 \%$ sucrose was the most accepted by the consumers, according to Figures 1 and 2. Thus, this value was used as reference for the ideal sucrose concentration.

Table 1. Acceptance means of chocolate ice cream overall liking $(n=122)$

\begin{tabular}{cc}
\hline Sucrose concentration (\%) & Overall liking $^{1}$ \\
\hline $12 \%$ & $5.10^{\mathrm{a}}$ \\
$14 \%$ & $4.94^{\mathrm{ab}}$ \\
$16 \%$ & $4.52^{\mathrm{ab}}$ \\
$18 \%$ & $3.55^{\mathrm{c}}$ \\
$20 \%$ & $4.38^{\mathrm{b}}$ \\
$\mathrm{MDS}^{2}$ & 0.63 \\
\hline
\end{tabular}

1 Means in a column followed by different letters are significantly different $(\mathrm{P} \leq 0.05)$.

2 MDS: minimum significant difference.

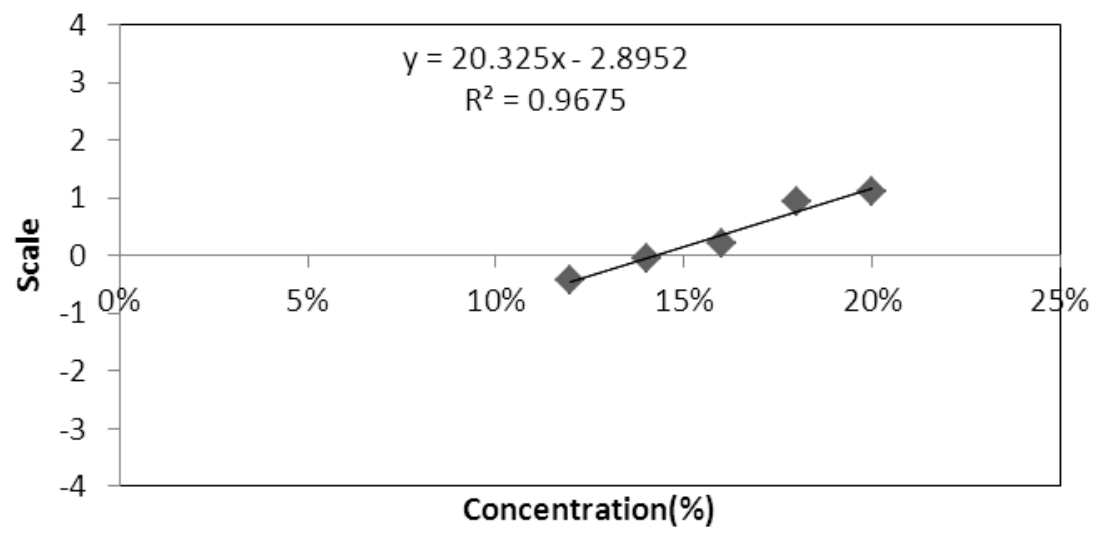

Figure 1. Ideal scale: Regression equation and average coefficient as a function of sucrose concentration in chocolate ice cream 


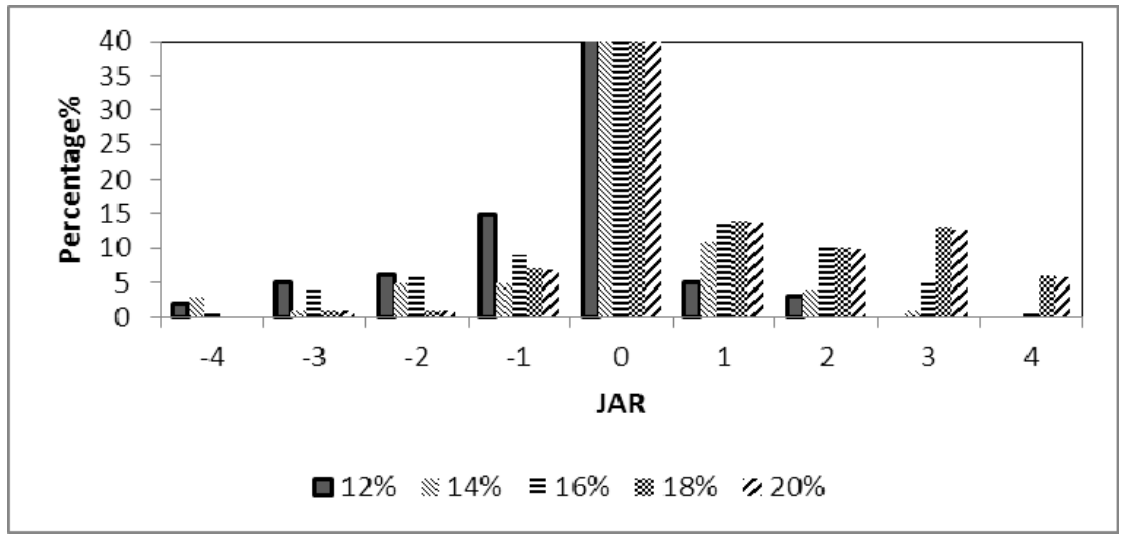

Figure 2. JAR percentage of five sucrose concentration of chocolate ice cream

Among the evaluated attributes, chocolate flavor and smoothness were the more significantly responsible for the penalty analysis of chocolate ice cream acceptance, according to Table 2 .

Table 2. Mean effects of penalty analysis

\begin{tabular}{llll}
\hline Variable & Level & $\%$ & Mean effects \\
\hline Sweetness & Not sweet enough & 11.881 & 2.613 \\
& Too sweet & 9.901 & -0.104 \\
Chocolate flavor & Not chocolate flavor enough & 23.762 & 2.226 \\
& Too chocolate flavor & 13.861 & -0.833 \\
Smoothness & Not enough smooth & 28.713 & 2.063 \\
& Too smooth & 4.950 & -1.275 \\
\hline
\end{tabular}

Figure 3 shows that $24 \%$ of the consumers, which hit results of overall impression, increased their approval of the ice cream with $14 \%$ sucrose in 2 points. They felt the sample had less chocolate flavor than they would like to eat. 


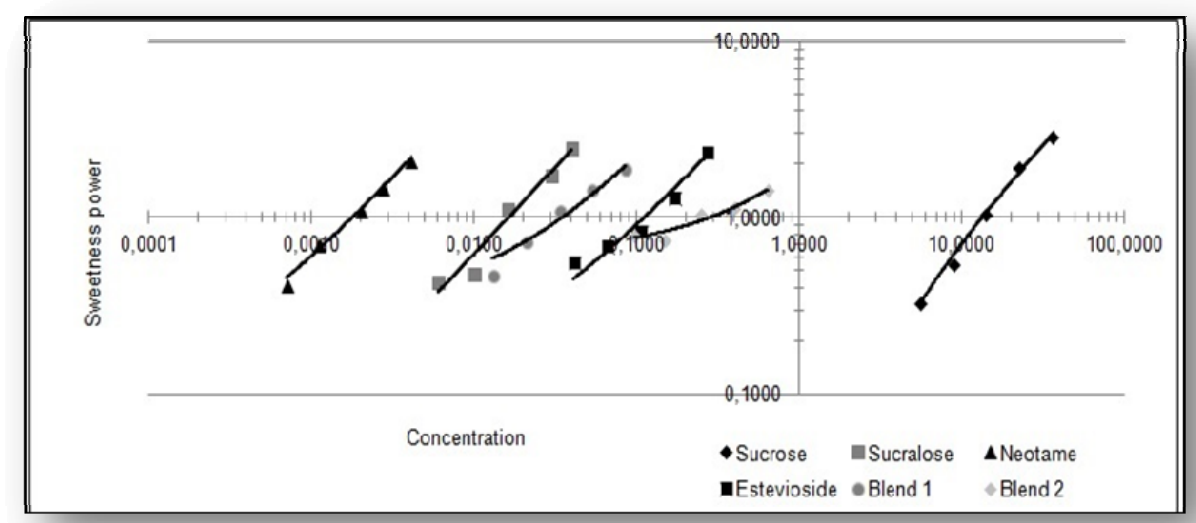

Figure 3. Power function for chocolate ice cream (x-axis shows the concentration of the sweeteners (\%) and y-axis shows the values of the normalized estimated magnitudes)

A sample with attributes in the upper right-hand corner of the penalty plot is considered worse than one with attributes located in the lower left-hand corner. The "desired response" is attributes located in the lower left area, meaning that only a few consumers state that the attribute level is not right and the impact on overall liking is small.

According to Laguna et al. (2013), penalty analysis based on JAR scales showed that excessive hardness and dry mouthfeel were the most penalizing sensory characteristics causing significant drop in biscuit acceptability.

Another study using penalty analysis evaluated French wines and the results permitted to rank the descriptors in relation with the typicality concept (Cadot et al., 2010).

Penalty analysis based on the comparison of consumer perception of the samples and their ideal product provided information about the impact of deviation from the ideal on liking scores, directly from consumers (Ares et al., 2014).

\subsection{Equi-sweetness Determination}

The equi-sweetness was calculated aiming to provide the same sweet taste of $14 \%$ sucrose in chocolate ice cream. According to the results presented in Table 3, it was possible to estimate the sweetness power of each sucrose replacement. 


\section{Macrothink}

Table 4. Acceptance means of diet chocolate ice cream samples $(n=116)$

\begin{tabular}{ccccccc} 
Sweetener Slope (b) $\begin{array}{c}\text { Interception } \\
\text { ordinate (a) }\end{array}$ & $\mathrm{R}^{2}$ & Power Function $^{1}$ & $\begin{array}{l}\text { Equivalent } \\
\text { sweetness } \\
(\%)\end{array}$ & $\begin{array}{l}\text { Sweetener } \\
\text { Power }\end{array}$ \\
\hline Tra & 1.195442 & -1.3706 & 0.994834 & $\mathrm{P}=0.0426 . \mathrm{C}^{1.195}$ & - & - \\
Suc & 0.969128 & 1.7325 & 0.958128 & $\mathrm{P}=54.0156 . \mathrm{C}^{0.696}$ & 0.0169 & 828 \\
Neo & 0.904906 & 2.4938 & 0.995178 & $\mathrm{P}=311.7100 . \mathrm{C}^{0.905}$ & 0.0017 & 8235 \\
Ste & 0.738961 & 0.7216 & 0.936159 & $\mathrm{P}=6.0480 . \mathrm{C}^{0.739}$ & 0.0874 & 160 \\
BL1 & 0.728068 & 1.0765 & 0.987795 & $\mathrm{P}=11.926 . \mathrm{C}^{0.728}$ & 0.0330 & 424 \\
BL2 & 0.342007 & 0.2134 & 0.909958 & $\mathrm{P}=1.6345 . \mathrm{C}^{0.342}$ & 0.2369 & 59 \\
\hline
\end{tabular}

${ }^{1}$ Power function with the following characteristics: $\mathrm{S}=\mathrm{aC}^{\mathrm{n}}$, where " $\mathrm{S}$ " is the perceived sensation, "C" is the stimulus concentration, " $\mathrm{a}$ " is the slope of the straight line obtained.

Using the position of the curves observed in Figure 4, it is possible to identify the ratio of the sweetness associated with the sweeteners used. The sucrose curve is distant from the others, indicating that higher sucrose concentration is necessary to achieve the same sweetness sensation. Neotame is the furthest from sucrose, indicating that a lower concentration of this substance is required to express the same sweetness as sucrose.

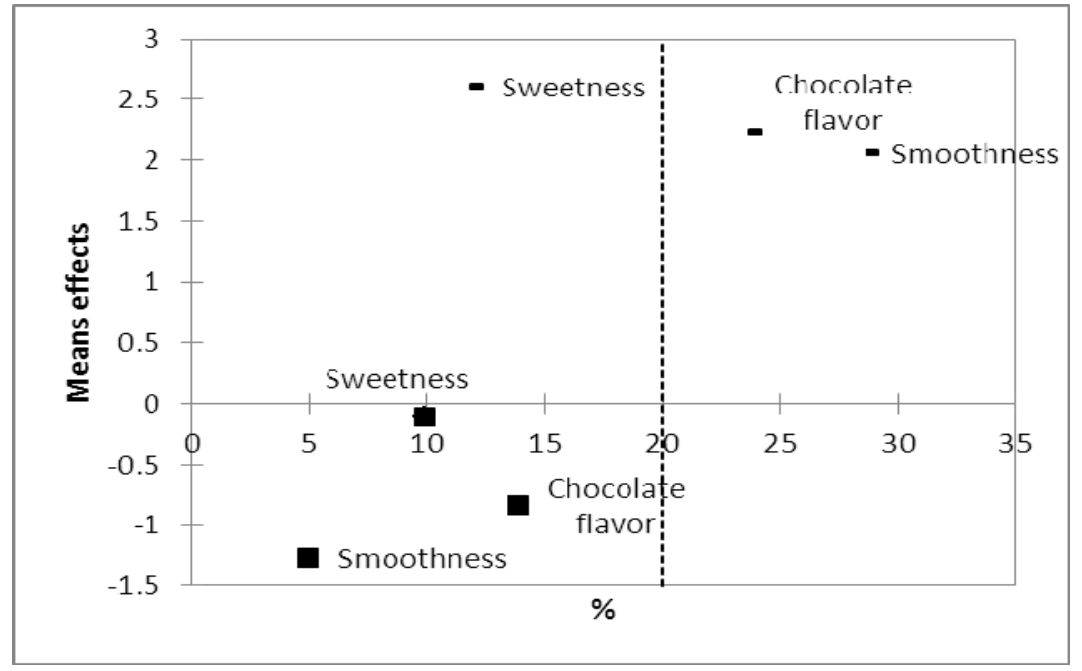

Figure 4. Penalties (drops in liking) by proportion of consumers (cut point was $20 \%$ of consumers stating that an attribute was "not enough" $(-)$ or "too much" $(+))$

Other studies reported the sweetening power of each sweetener, however, in our research a significantly high sucralose value (828) was observed, compared with values of 636 in instant coffee and 599 in ground roasted coffee (MORAES \& BOLINI, 2010), 629 in peach nectar (Cardoso \& Bolini, 2007), 261 in strawberry-flavored Petit Suisse cheese (De Souza et al., 2011) and 570 in diet chocolate (Palazzo et al., 2011). 
Therefore, to show the acceptance of diet chocolate ice cream formulations, the hedonic means (Table 4) were analyzed.

Table 5. Acceptance Means of six chocolate ice cream samples $(n=116)$

\begin{tabular}{llllll}
\hline Samples & Appearence & Aroma & Flavor & Texture & Overall liking \\
\hline Sucrose (Pad) & $5.68^{\mathrm{a}}$ & $5.68^{\mathrm{ab}}$ & $6.17^{\mathrm{ab}}$ & $5.84^{\mathrm{ab}}$ & $6.01^{\mathrm{ab}}$ \\
Sucralose (Suc) & $5.70^{\mathrm{a}}$ & $4.94^{\mathrm{c}}$ & $3.89^{\mathrm{d}}$ & $5.20^{\mathrm{bc}}$ & $4.51^{\mathrm{c}}$ \\
Neotame (Neo) & $5.86^{\mathrm{a}}$ & $5.21^{\mathrm{bc}}$ & $5.54^{\mathrm{d}}$ & $4.65^{\mathrm{c}}$ & $4.16^{\mathrm{c}}$ \\
Stevioside (Est) & $6.23^{\mathrm{a}}$ & $5.41^{\mathrm{abc}}$ & $4.89^{\mathrm{c}}$ & $5.95^{\mathrm{a}}$ & $5.43^{\mathrm{b}}$ \\
Blend 1 (Bl1) & $6.17^{\mathrm{a}}$ & $5.61^{\mathrm{ab}}$ & $5.81^{\mathrm{b}}$ & $6.29^{\mathrm{a}}$ & $4.07^{\mathrm{a}}$ \\
Blend 2 (Bl2) & $6.05^{\mathrm{a}}$ & $5.88^{\mathrm{a}}$ & $6.66^{\mathrm{a}}$ & $6.32^{\mathrm{a}}$ & $6.34^{\mathrm{a}}$ \\
MDS & 0.66 & 0.55 & 0.72 & 0.71 & 0.61 \\
\hline
\end{tabular}

Means in a column followed by different letters are significantly different $(\mathrm{P} \leq 0.05)$.

There was no significant difference among the samples in relation to their appearance.

The diet chocolate ice cream sweetened with sucrose associated with the aroma compound (BL2) showed a significant result, represented by all acceptance attributes means compared with the standard sample (Tra).

However, the best sweetener able to replace sucrose in chocolate ice cream was the neosucralose blend (BL1). None of its attributes differed $(p \leq 0,05)$ from the sucrose sample. This fact could be explained by the synergistic effect of sucralose, neotame and potassium acessulfame. Other works have already reported this effect with blend sweeteners on food and beverages (Paixão et al., 2014, Rodrigues et al., 2015).

It's important to emphasize the stevioside (Ste) behavior, which showed no difference between the sucrose sample in relation to appearance, aroma, texture and overall liking.

On the other hand, sucralose (Suc), usually associated with the better sucrose replacement, showed different means among the standard samples (aroma, flavor and overall liking). Also, neotame, whose flavor, texture and overall liking characteristics were significantly different from the sucrose sample.

A recent study determined the physicochemical characteristics and sensory profile of mango nectar sweetened with different high intensity sweeteners throughout storage time. In its conclusions, in the graphic illustration, the consumers were represented close to samples with neosucralose and stevioside, suggesting that these people preferred the mango nectar samples sweetened with these sweeteners (Cadena et al., 2013).

Effects of different bulk sweeteners (maltitol, isomalt, and xylitol) with different particle size intervals on rheological properties of molten chocolate were investigated and maltitol resulted in similar rheological properties of chocolate compared to sucrose (Sokmen \& Gunes, 2006). In this study, maltitol presence in chocolate ice cream was successful and can, thus, be a good alternative to diet purposes. 
Still, it's not possible to foresee or generalize the sweetener's behavior without a complete consumers survey.

\section{Conclusions}

JAR assists researchers in understanding why consumers like or dislike a product and guiding food development efforts aimed at increasing consumer acceptability. The penalty analysis method was able to characterize chocolate ice cream samples using consumers' perceptions and help identifying the attributes that are significant to increase the acceptance.

The use of an aroma able to decrease the sucrose concentration is an innovation in this field. The significant obtained results could be useful for different diet food and beverages manufactures and they could also help others sensory scientific studies looking for sucrose replacement.

\section{Acknowledgment}

The authors thank CNPq for granting the doctoral scholarship (Process 502709/2014-6).

\section{References}

Aykan, V., Sezgin, E., \& Guzel-seydim, Z. B. (2008). Use of fat replacers in the production of reduced-calorie vanilla ice cream. Eur $J$ Lipid Sci Technol, 110, 516-20. https://doi.org/10.1002/ej1t.200700277

Amerine, M. A., Pangborn, R. M., \& Roessler, E. B. (1965). Principles of sensory evaluation of food Academic Press. New York/London.

Ares, G., Barreiro, C., \& Giménez, A. (2008). Comparison of attribute looking and jar scales to evaluate the adequacy of sensory attributes of milk desserts. J Sens Stud, 24, 664-76. https://doi.org/10.1111/j.1745-459X.2009.00232.x

Ares, G., Dauber, C., Fernandez, E., Giménez, A., \& Varela, P. (2014). Penalty analysis based on CATA questions to identify drivers of liking and directions for product reformulation. Food Qual Prefer, 32, 65-76. http://dx.doi.org/10.1016/j.foodqual.2013.05.014

Biosystemes. (2009). Software solutions for sensory analysis and consumer tests. Fizz sensory software version $2.40 \mathrm{~h}$. Couternon, France.

Cadena, R. S., \& Bolini, H. M. A. (2011). Time-intensity analysis and acceptance test for traditional and light vanilla ice cream. Food Res Int, 44, 677-83. http://dx.doi.org/10.1016/j.foodres.2010.12.012

Cadena, R. S., \& Bolini, H. M. A. (2012). Ideal and relative sweetness of high intensity sweeteners in mango nectar. Int $J$ Food Sci Technol, 47(5), 991-6. https://doi.org/10.1111/j.1365-2621.2011.02932.x

Cadena, R. S., Cruz, A. G., Netto, R. R., Castro, W. F., Faria, J. A. F., \& Bolini, H. M. A. (2013). Sensory profile and physicochemical characteristics of mango nectar sweetened with high intensity sweeteners throughout storage time. Food Res Int, 54(2), 1670-9. http://dx.doi.org/10.1016/j.foodres.2013.10.012

Cadot, Y., Caillé, S., Samson, A., Barbeau, G., \& Cheynier, V. (2010). Sensory dimension of 


\section{MInstitute Macrothink $_{\text {Int }}$}

wine typicality related to a terroir by quantitative descriptive analysis, just about right analysis and typicality assessment. Anal Chim Acta, 660, 53-62. http://dx.doi.org/10.1016/j.aca.2009.10.006

Cardoso, J. M. P., \& Bolini, H. M. A. (2007). Different sweeteners in peach nectar: ideal and equivalent sweetness. Food Res Int, 40(10), 1249-53. http://dx.doi.org/10.1016/j.foodres.2007.08.004

Cardoso, J. M. P., \& Bolini, H. M. A. (2008). Descriptive profile of peach nectar sweetened with sucrose and different sweeteners. $J$ Sens Stud, 23, 804-16. https://doi.org/10.1111/j.1745-459X.2008.00187.x

Cervantes, B. G., Aoki, N. A., \& Almeida, C. P. M. (2010). Sensory acceptance of fermented cassava starch biscuit prepared with flour okara and data analysis with penalty analysis methodology. Brazilian Journal of Food Technology, $6^{\text {th }}$ Sensiber, ago, 3-10.

De Souza, V. R., Pinheiro, A. C. M., Carneiro, J. D. D. S., Pinto, S. M., Abreu, L. R., \& Menezes, C. C. (2011). Analysis of various sweeteners in petit suisse cheese: determination of the ideal and equivalent sweetness. $J$ Sens Stud, 26, 339-45. https://doi.org/10.1111/j.1745-459X.2011.00349.x

Fonseca, F. G. A., Esmerino, E. A., Filho, E. R. T., Ferraz, J. P., Cruz, A. G., \& Bolini, H. M. A. (2016). Novel and successful free comments method for sensory characterization of chocolate ice cream: a comparative study between pivot profile and comment analysis. $J$ Dairy Sci, 99(5), 3408-20. http://dx.doi.org/10.3168/jds.2015-9982

Laguna, L., Varela, P., Salvador, A., \& Fiszman, S. (2013). A new sensory tool to analyse the oral trajectory of biscuits with different fat and fiber contents. Food Res Int, 51, 544-53. http://dx.doi.org/10.1016/j.foodres.2013.01.003

Macfie, H. J., Bratchell, N., Greenhoff, K., \& Vallis, L. V. (1989). Designs to balance the effect of order of presentation and first-order carry-over effect in halls tests. J Sens Stud, 4(2), 129-48. https://doi.org/10.1111/j.1745-459X.1989.tb00463.x

Maia, M. C. A., Galvão, A. P. G. L. K., Modesta, R. C. D., \& Júnior, N. P. (2008). Consumer evaluation of ice cream with xylitol. J Food Sci Technol, 28(2), 341-47. http://dx.doi.org/10.1590/S0101-20612008000200011

Marcellini, P. S., Chainho, T. F., \& Bolini, H. M. A. (2005). Ideal sweetness and acceptance analysis of reconstituted concentrated pineapple juice sweetened with different sweeteners and sucrose. Food Nut J, 16, 177-82.

Moraes, T., Barbosa, P. C., \& Bolini, H. A. M. (2010). Different sweeteners in beverages prepared with instant and roasted ground coffee: ideal and equivalent sweetness. J Sens Stud, 25(1), 215-25.

Morais, E. C., Morais, A. R., Cruz, A. G., \& Bolini, H. M. A. (2014). Development of chocolate dairy dessert with addition of prebiotics and replacement of sucrose with different $\begin{array}{lllll}\text { high-intensity } \quad \text { sweeteners. } & J & \text { Dairy } & \text { Sci, } & 97(5),\end{array}$ 
http://dx.doi.org/10.3168/jds.2013-7603

Ozdemir, C., Arslaner, A., \& Ozdemir, S. (2015). The production of ice cream using stevia as a sweetener. J Food Sci Technol, 52(11), 7545-48. https://doi.org/10.1007/s13197-015-1784-5

Paixão, J. A., Rodrigues, J. B., Esmerino, E. A., Cruz, A. G., \& Bolini, H. M. A. (2014). Influence of temperature and fat content on ideal sucrose concentration, sweetening power, and sweetness equivalence of different sweeteners in chocolate milk beverage. J Dairy Sci 97(12), 7344-53. http://dx.doi.org/10.3168/jds.2014-7995

Palazzo, A. B., Carvalho, M. A. R, Efraim, P., \& Bolini, H. M. A. (2011). The determination of isosweetness concentrations of sucralose, rebaudioside and neotame as sucrose substitutes in new diet chocolate formulations using the time-intensity analysis. J Sens Stud, 26, 291-7. https://doi.org/10.1111/j.1745-459X.2011.00344.x

Palazzo, A. B., \& Bolini, H. M. A. (2014). Multiple time-intensity analysis: sweetness, bitterness, chocolate flavor and melting rate of chocolate with sucralose, rebaudioside and neotame. J Sens Stud, 29, 21-32. https://doi.org/10.1111/joss. 12078

Plaehn, D., \& Horne, J. (2008). A regression-based approach for testing significance of "just-about-right" variable penalties. Food Qual Prefer, 19(1), 21-32. http://dx.doi.org/10.1016/j.foodqual.2007.06.003

Rodrigues, J. B., Paixão, J. A., Cruz, A. G., \& Bolini, H. M. A. (2015). Chocolate milk with chia oil: ideal sweetness, sweeteners equivalence, and dynamic sensory evaluation using a time-intensity methodology. $J \quad$ Food $\quad$ Sci, $\quad 80(12), \quad$ s2944-49. https://doi.org/10.1111/1750-3841.13120

SAS System for windows (statistical analysis system). (2003). Version 9.1.3 service pack 3. SAS Institute Inc. 2002-2003. Carry. NC. USA.

Sokmen, Q., \& Gunes, G. (2006). Influence of some bulk sweeteners on rheological properties of chocolate. Lwt Food Sci Technol, 39(10), 1053-1058. http://dx.doi.org/10.1016/j.1wt.2006.03.002

Soukoulis, C., \& Tzia, C. (2010). Response surface mapping of the sensory characteristics and acceptability of chocolate ice cream containing alternative sweetening agents. J Sens Stud, 25, 50-75. https://doi.org/10.1111/j.1745-459X.2009.00246.x

Stone, H., \& Oliver, S. M. (1969). Measurement of the relative sweetness of selected sweeteners and sweetener mixtures. $J$ Food Sci, 34(2), 215-22. https://doi.org/10.1111/j.1365-2621.1969.tb00922.x

Sun-Waterhouse, D., Edmonds, L., Wadhwa, S. S., \& Wibisono, R. (2013). Producing ice cream using a substantial amount of juice from kiwifruit with green, gold or red flesh. Food Res Int, 50, 647-656. http://dx.doi.org/10.1016/j.foodres.2011.05.030

Xiong, R., \& Meullenet, J. F. (2006). A PLS dummy variable approach to assess the impact of jar attributes on liking. Food Qual Prefer, 17(3), 188-198. 


\section{Macrothink}

http://dx.doi.org/10.1016/j.foodqual.2005.03.006

\section{Copyright Disclaimer}

Copyright for this article is retained by the author(s), with first publication rights granted to the journal.

This is an open-access article distributed under the terms and conditions of the Creative Commons Attribution license (http://creativecommons.org/licenses/by/3.0/). 